\title{
A SANGRE Y FUEGO. ANTONIO ROYO VILLANOVA, MAESTRO DE ADMINISTRATIVISTAS Y DE ANTICATALANISTAS ${ }^{1}$
}
A SANGRE Y FUEGO. ANTONIO ROYO VILLANOVA, MASTER FOR ADMINISTRATIVISTS AND ANTICATALANISTS

\author{
Josep Pich Mitjana, José Contreras Ruiz y Juan Pastrana Piñero \\ Universitat Pompeu Fabra
}

Entregado el 22-5-2014 y aceptado el 11-3-2015.

\begin{abstract}
Resumen: Este artículo es una aproximación a la trayectoria ideológica del catedrático, periodista, político y escritor Antonio Royo Villanova, y su posicionamiento en relación con el nacionalismo catalán. Influyente autor en el derecho Administrativo español, Royo Villanova mostró un persistente discurso anticatalanista a lo largo de su carrera periodística y política. Si bien fue un defensor de la descentralización administrativa, se opuso radicalmente a cualquier descentralización política y cultural. Su furibundo anticatalanismo le hizo uno de los políticos más populares de la II República. Después de su muerte, cayó en el olvido, a pesar de que su concepción del derecho administrativo español fue posiblemente la predominante en la academia española durante la primera mitad del siglo xx. La influencia de su pensamiento político, entre los defensores del unitarismo, así como su legado periodístico y académico son muy am-
\end{abstract}

\footnotetext{
1 Este estudio forma parte del proyecto de investigación: «Las problemáticas federalistas españolas, siglos XIX-XX», HAR2011-28572 sufragado por el Ministerio de Ciencia e Innovación. Agradecemos a los Drs. Juan Sisinio Pérez Garzón y Ricardo Robledo Hernández la lectura crítica de este artículo, aunque los errores únicamente son atribuibles a los autores.
} 
plios. Fue un regeneracionista, un académico relevante defensor de la descentralización de la administración, siempre que no cuestionase la unidad española, un político que llegó a ministro y un maestro tanto de anticatalanistas como de administrativistas.

Palabras clave: Antonio Royo Villanova, descentralización administrativa, regeneracionismo, anticatalanismo, nacionalismo.

\begin{abstract}
This article examines the ideological trajectory of the Professor, journalist, politician and writer Antonio Royo Villanova, and its position in relation to Catalonian nationalism. Influential author in the field of administrative law, Royo Villanova showed a persistent anticatalanist speech throughout his journalistic and political career. His furious anti-catalanism made him one of the most popular politicians of the Second Republic. After his death, his political thinking was forgotten, although his conception of the Spanish administrative law was possibly the most influential in the Spanish academy during the first half of the twentieth century. His political thought between the advocates of Unitarianism and his journalistic and academic legacy have been very large. It was a regenerationist, a relevant academic, an advocate of administrative decentralization, provided that it does not question the Spanish union, a politician who became a minister and a master for both anti-catalanist, and professors in administrative law.
\end{abstract}

Key words: Antonio Royo Villanova, administrative decentralization, regenerationist, anti-catalanism, nationalism. 
Este artículo se centra en el estudio del catedrático, político, periodista y escritor aragonés de origen y vallisoletano de adopción Antonio Royo Villanova (1869-1958). La historiografía española se ha mostrado tradicionalmente crítica con los estudios biográficos ya que eran vistos como un género «híbrido o impuro»; ${ }^{2}$ sin embargo, pueden ser útiles para impulsar nuevos conceptos de la historia política si aceptamos que «un individuo no puede explicar completamente un grupo, una comunidad o una institución, y viceversa, un grupo, una comunidad o una institución no puede explicar completamente un individuo». ${ }^{3}$

Antonio Royo Villanova basó su actividad política en una oposición frontal y visceral a los planteamientos catalanistas, con lo que consiguió una gran popularidad durante la Segunda República. Después de su muerte cayó en el olvido, aunque se le recordaba como un «maestro de anticatalanistas». ${ }^{4}$ En el ámbito del derecho Administrativo, su influencia fue más persistente. Así, la Revista de Administración Pública (en adelante RAP) que fundó Eduardo García de Enterría (1923-2013) en 1950, y es la publicación de referencia en derecho administrativo, tanto en España como en Latinoamérica, ${ }^{5}$ ante la noticia de la muerte de Royo Villanova, publicó que se unía al «duelo general» y al propósito de «rendirle el homenaje que merece». ${ }^{6}$ No fueron meras palabras, ya que la Universidad de Valladolid acordó que el Seminario de Derecho Administrativo llevase su nombre, «según acuerdo unánime que la Junta de Facultad adoptó a propuesta de (...) Eduardo GARCÍA DE ENTERRÍA». ${ }^{7}$ La RAP, de la mano del catedrático en Derecho Administrativo Luís Jordana de Pozas (18901983), ${ }^{8}$ aseguraba que recordaban a Royo Villanova «cuando excitaba con

2 Pedro Ruiz Torres, «Las repercusiones de los cambios culturales de la modernidad en el modo de pensar la biografía», Ayer, n. ${ }^{\circ}$ 93, 2014, pp. 20 y 46.

3 Isabel Burdiel, «Historia política y biografía: más allá de las fronteras», Ayer, op. cit., pp. 47 y 69-70.

${ }^{4}$ Enric Ucelay-Da Cal, El imperialismo catalán. Prat de la Riba, Cambó, D’Ors y la conquista moral de España, Edhasa, Barcelona, 2003, p. 329.

5 http://www.cepc.gob.es/publicaciones/revistas/revistaselectronicas/listadorevistas/revista01/presentacion01.3/2/2014. 16:44.

${ }^{6}$ Luis Jordana de Pozas, «In Memoriam: Don Antonio Royo-Villanova», Revista de administración pública, $\mathrm{n}^{\circ}{ }^{\circ} 27,1958, \mathrm{pp} .162$.

7 Sebastián Martín-Retortillo, «Memoria de don Antonio Royo Villanova», Revista de administración pública, n. ${ }^{\circ} 40,1963$, p. 413.

8 Véase su necrológica en http://elpais.com/diario/1983/10/25/ agenda/435884401_850215.html.3/2/2014.15:59. 
su ejemplo, su pluma y su palabra a combatir al separatismo» y pregonaba la necesidad de hacerlo «a sangre y fuego». ${ }^{9}$

\section{La familia y el periodismo}

Royo nació el 12 de junio de 1869 en Zaragoza. Era hijo de Pilar Villanova Perena ( $i-1914)$ y de Mariano Royo Urieta (1825-1900), ingeniero de caminos, canales y puertos. ${ }^{10}$ Los principios regeneracionistas defendidos por el padre ${ }^{11}$ posiblemente influyeron en los trece hijos que tuvo el matrimonio, especialmente en el periodista Luís Royo Villanova (1866-1900) fundador de la popular revista satírica Gedeón en 1895; el médico Ricardo Royo Villanova (1868-1943), catedrático de Patología Médica y rector de la Universidad de Zaragoza, entre 1913 y 1928, Mariano Royo Villanova que siguió los pasos de su padre en el ámbito de la ingeniería, y el propio Antonio Royo Villanova que descolló en su tarea universitaria, así como en la periodística y en la política. ${ }^{12}$ Una saga que continuaron los profesores Ricardo Royo-Villanova Morales (1899-1975), que fue catedrático de medicina legal en la Universidad de Valladolid desde 1928, y Segismundo Royo-Villanova Fernández-Cavada (1909-1965), catedrático de Derecho Administrativo en las universidades de Santiago de Compostela y de Madrid, en esta última ejerció de rector entre 1956 y $1964 . .^{13}$

${ }^{9}$ Luis Jordana de Pozas, «In Memoriam...», op. cit., p. 159. La influencia de Royo Villanova entre los administrativistas españoles es evidente en el estudio del catedrático en Derecho Administrativo, en el pasado vinculado al PSOE y actualmente a UPyD, Francisco Sosa Wagner, Juristas en la II República. Los iuspublicistas, Marcial Pons, Madrid, 2009. Libro que ha sido ampliamente comentado y criticado por Sebastián Martín, «Sobre olvidos históricos, semblanzas jurídicas y estrategias políticas», Cuadernos del Instituto Antonio de Nebrija de estudios sobre la Universidad, vol.12, n. 2, 2009, pp. 217-242.

$10 \mathrm{http} / / / \mathrm{www} . e n c i c l o p e d i a-\operatorname{aragonesa.com/voz.asp?voz\_ id=11030.~3/2/2014.~16:20.~}$ Véase también L. Jordana de Pozas, «In Memoriam...», op. cit., p. 159 y Sebastián Martín-Retortillo, «Memoria de...», op. cit., pp. 414-415.

${ }^{11}$ Sebastián Martín-Retortillo, «Memoria de...», op. cit., p. 415.

12 Luis Jordana de Pozas, «In Memoriam...», op. cit., p. 159.

13 José María Puyol Montero, «ROYO VILLANOVA FERNÁNDEZ-CAVADA, Segismundo (1909-1965)», Diccionario de catedráticos españoles de Derecho, 2012, en http://portal.uc3m.es/portal/page/portal/instituto_figuerola/programas/phu/diccionariodecatedraticos/lcatedraticos/fcavada. 3/2/2014. 17:10. 
Antonio Royo Villanova estudió y se licenció en la Universidad de Zaragoza. Se doctoró en Madrid, con la tesis Los contratos aleatorios en el Código civil español y en los extranjeros. ${ }^{14}$ En 1893 ingresó como profesor auxiliar de la Universidad de Zaragoza encargado de la cátedra de Derecho Civil. Su trayectoria como civilista se truncó al obtener en «reñidas oposiciones», en 1895, la cátedra de Derecho Político y Administrativo en la Universidad de Valladolid. A Royo le gustaba citar la frase de Joaquín Costa (1846-1911) que «España tiene que encerrarse en la Escuela y en la Universidad, como en un nuevo claustro materno». ${ }^{15}$

En 1900, se acordó la separación del derecho político del administrativo y, desde el 2 de agosto de aquel año, ocupó la cátedra de Derecho Administrativo. Por Real Orden de 1902 le concedieron el traslado a la Universidad de Zaragoza, pero en 1906 volvió a ser nombrado catedrático numerario de Derecho Administrativo de la Universidad de Valladolid, y la mantuvo hasta su jubilación. La mayor parte de su producción académica estaba relacionada con el Derecho Administrativo. Es especialmente relevante su manual titulado Principios de Derecho Administrativo, aunque, posteriormente, lo tituló Elementos de Derecho Administrativo. La primera edición es de 1900, pero hasta su muerte se reeditó en veinticuatro ocasiones, la última en 1956, cuando fue puesta al día por su hijo. En 1964, un año antes de la muerte de Segismundo Royo-Villanova, se publicó la 26. ${ }^{\text {a }}$ edición. ${ }^{16}$

El manual de Royo Villanova fue la obra de referencia de los administrativistas españoles durante la primera mitad del siglo XX. Se fundamentaba en adaptar las teorías administrativistas a la realidad de la administración española y en rechazar que tanto la provincia como el municipio

14 Expediente académico de Antonio Royo Villanova, alumno de la Facultad de Derecho de la Universidad Central. Natural de Zaragoza (Capital). Licenciado en Derecho (Zaragoza); Doctor en Derecho. Archivo Histórico Nacional. ES.28079.AHN/2.3.1.20.4.1// UNIVERSIDADES,4691,Exp.7.

${ }_{15}$ Luis Jordana de Pozas, «In Memoriam...», op. cit., p. 160. Sebastián Martín-Retortillo, «Memoria de...», op. cit., p. 417.

16 Sebastián Martín-Retortillo, «Memoria de...», op. cit., pp. 417-418. María Teresa Gutiérrez Rodríguez, «Perfil y trayectoria política del diputado don Antonio Royo Villanova», en DD. AA., Las Cortes de Castilla y León, 1188-1988: Actas de la tercera etapa del Congreso Científico sobre la historia de las Cortes de Castilla y León, del 26 a 30 de septiembre de 1988, vol. 2, Cortes de Castilla y León, Valladolid, 1988, p. 597. Véase también Antonio Royo-Villanova, Elementos de Derecho Administrativo, Valladolid, revisión de Segismundo Royo-Villanova, 26a ed., 2 vols, Santarén, Valladolid, 1964, pp. 999. 
fuesen órganos del Estado. Por tanto, defendía la descentralización administrativa española. También tenía una preocupación didáctica, y en una disciplina caracterizada por una producción académica enrevesada utilizaba un estilo sencillo y claro por lo que era uno de los maestros «más considerados por las generaciones posteriores de administrativistas». ${ }^{17}$

Se casó con la vallisoletana Consuelo Fernández-Cavada Bustamante (i-1964) ${ }^{18}$ En Valladolid, a cuya Universidad pertenecía su cátedra, continuó su faceta periodística iniciada en Zaragoza, donde dirigió el Diario de Avisos - del que su familia era copropietaria hasta que lo vendió al $\mathrm{He}$ raldo de Aragón, en 1911-, mientras que en la ciudad castellana fue director de El Norte de Castilla, entre los años 1903 y 1905, - diario fundado en 1854, que pasó a ser propiedad de César Silió Cortés (1865-1944) y de Santiago Alba Bonifaz (1872-1949), desde $1893-{ }^{19}$ y del que posteriormente sería director de su Consejo de Administración, entre 1912 y 1956. Sus herederos continuaron vinculados a la propiedad del periódico hasta su incorporación, en 1994, al Grupo Correo que, posteriormente, se transformó en Vocento. ${ }^{20}$

Sus coetáneos afirmaban que fue un gran periodista, que se caracterizaba por una «pluma ágil» e intencionada. Escribió centenares de artículos, y éstos eran recordados como una «sucesión de ingeniosas crónicas sobre los temas políticos y administrativos más actuales durante los

17 Luis Jordana de Pozas, «In Memoriam...», op. cit., pp. 160-161. La referencia de su

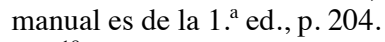

18 Véase su necrológica en: http://hemeroteca.abc.es/nav/Navigate.exe/hemeroteca/ madrid/abc/1964/02/29/060.html. 4/2/2014. 16:44.

19 Ricardo Robledo Hernández, «L'actitud castellana enfront del catalanisme», Recerques, n..$^{\circ}$, 1975, pp. 224-225, especialmente la nota 16. Juan Antonio Cano García, «El conservadurismo vallisoletano en la segunda restauración: César Silió», Investigaciones Históricas. Época Moderna y Contemporánea, n. ${ }^{\circ} 15,1995$, pp. 97-105, y del mismo autor «El componente económico en la configuración de la elite política vallisoletana», Investigaciones Históricas. Época Moderna y Contemporánea, n. ${ }^{\circ}$ 18, 1998, pp. 217-234. Véase también: http://canales.elnortedecastilla.es/150aniversario2/especial/1887personas.html. 4/2/2014. 16:44.

${ }^{20}$ La historia del diario estuvo, de hecho, vinculada a varias familias muy concretas, tal como se pone de manifiesto en http://canales.elnortedecastilla.es/150aniversario2/ especial/1957empresa.html. 3/2/2014. 16:25, y http://www.filosofia.org/ave/001/a333.htm. 5/2/2014. 18:14, y http://www.vocento.com/regionales_prensa.php. 6/2/2014. 9:47. Véase también Celso Almuiña, La prensa vallisoletana durante el siglo XIX, Ed. Institución Cultural Simancas, Valladolid, 1977 y María Teresa Gutiérrez Rodríguez, «Perfil y trayectoria...», op. cit., pp. 597-598. 
años transcurridos desde la pérdida de las colonias hasta el Alzamiento nacional». ${ }^{21} \mathrm{El}$ ambiente familiar, su preparación y su temperamento se impusieron a su labor periodística y, a principios del siglo XX, inició su carrera política vinculado al partido liberal.

\section{Regeneracionismo, actividad política y anticatalanismo}

Durante su juventud en Aragón, mientras se formaba como jurista y periodista, se integró en el «movimiento de regeneración nacional suscitado por el desastre de la guerra de Cuba y el desprestigio del régimen» 22 de la Restauración que impulsaban, entre otros, el cántabro Ricardo Macías Picavea (1847), que residió buena parte de su vida y murió en Valladolid en 1899, y el aragonés Joaquín Costa Martínez. ${ }^{23}$ Royo posiblemente ejerció de «puente» entre el pensamiento costista y los planteamientos regeneracionistas desarrollados en Valladolid por Macías Picavea. ${ }^{24}$

En 1896 publicó en Madrid, El problema de la soberanía en la Constitución española y, en 1899, La regeneración y el problema político. También fue editado el discurso, que pronunció ante el Congreso Católico de Burgos en 1899, sobre Las relaciones internacionales y los principios del catolicismo. Para difundir su visión de la descentralización adminis-

${ }^{21}$ Luis Jordana de Pozas, «In Memoriam...», op. cit., pp. 161-162.

22 Sebastián Martín-Retortillo, «Memoria de...», op. cit., p. 415.

23 George J.G. Cheyne, Joaquín Costa, el gran desconocido, Ariel, Barcelona, 1972 (reeditada el 2010). Sobre Joaquín Costa es fundamental la obra Cristóbal Gómez Benito (coord.), Joaquín Costa y la modernización de España, Congreso de los Diputados, Madrid, 2012, así como Eloy Fernández Clemente (coord.), Cuatro miradas sobre Costa, Real y Excma. Sociedad Económica Aragonesa de Amigos del País, Zaragoza, 2011, y también las obras de Eloy Fernández Clemente, Educación y revolución en Joaquín Costa, Cuadernos para el Diálogo, Madrid, 1969; J. Costa y el africanismo español, Porvivir, Zaragoza, 1977; Costa y Aragón, Rolde de Estudios Nacionalista Aragonés, Zaragoza, 1979, Joaquín Costa, regenerar España, Diputación General de Aragón, Zaragoza, 1986; Estudios sobre Joaquín Costa, Prensas Universitarias de Zaragoza, Zaragoza, 1989; El Pensamiento y la obra de Joaquín Costa, Institut de Ciències Polítiques i Socials, Barcelona, 1998; Lucas Mallada y Joaquín Costa, CAI, Zaragoza, 2000 y De la utopía de Joaquín Costa a la intervención del estado, un siglo de obras hidráulicas en España, Universidad de Zaragoza. Facultad de Ciencias Económicas y Empresariales, Zaragoza, 2000.

${ }^{24}$ Sebastián Martín-Retortillo, «Memoria de...», op. cit., p. 417. En la vinculación entre regeneracionismo y nacionalismo español son imprescindibles los primeros capítulos del libro de Ismael Saz, España contra España, Marcial Pons, Madrid, 2003, pp. 35-99. 
trativa fuera de la Universidad publicó La descentralización y el regionalismo, apuntes de actualidad, prologado por Joaquín Costa, ${ }^{25}$ al que estuvo vinculado el catalanófobo y españolista Royo Villanova ${ }^{26}$ hasta la muerte del político, jurista y escritor de Graus. ${ }^{27}$

Para Costa los programas de los partidos españoles de principios del siglo XX eran una mitología. En cambio, Royo Villanova, con su «preciosa monografía», interrumpía el proceso de «mitificación que se estaba obrando» sobre los vocablos regionalismo, descentralización o federalismo, ya que éstos no eran «especies fijas: cada uno de ellos ostenta variedad infinita de matices y grados, que no caben en molde tan angosto como el de un vocablo.» Consideraba que Royo era un «espíritu concreto, positivo y propiamente aragonés» que no habría caído en las redes del nominalismo al centrarse en los conceptos. Estudiando la normativa publicada en el diario oficial del Estado, y preguntándose qué competencias habían de ser únicamente estatales y las que tendrían que ser locales. También resaltaba su «doctrina sobre conciertos económicos, que es la cuestión batallona del día en esto del regionalismo». ${ }^{28}$

Costa aseguraba que el método usado por el catedrático vallisoletano pondría el problema regional español en vías de solución. Sin embargo, para el león de Graus la España de principios del siglo Xx tenía problemas «más sustanciales y de más urgente desenlace» que el regionalista, ya que éste afectaba a las «regiones menos sufridas contra los poderes centrales». No obstante, defendía la necesidad de reconocer la personalidad natural de los municipios y de las regiones que «todavía la conserven», para romper la dependencia centralista y cambiarla por una «moderada tutela». Este proceso descentralizador acabaría con la parálisis somnolienta que afectaba a España. Además, remarcaba que quien considera «secues-

25 Antonio Royo Villanova, La Descentralización y el regionalismo: apuntes de actualidad, Lib. de Cecilio Gasca, Zaragoza, 1900. Véase Andrés de Blas Guerrero, «Regeneracionismo español y cuestión nacional», Antonio Morales Moya, Juan Pablo Fusi Aizpurúa y Andrés de Blas Guerrero (dirs.), Historia de la nación y del nacionalismo español, Galaxia Gutenberg-Círculo de Lectores, Barcelona, 2013, pp. 572 y 579.

${ }^{26}$ Ricardo Robledo Hernández, «L'actitud castellana...», op . cit., pp. 232-233. Véase también Javier Moreno Luzón, «El españolismo de los liberales monárquicos en el reinado constitucional de Alfonso XIII» en Antonio Morales Moya, Juan Pablo Fusi Aizpurúa y Andrés de Blas Guerrero (dirs.), Historia de la nación..., op. cit., p. 590.

27 Sebastián Martín-Retortillo, «Memoria de...», op . cit., pp. 415-416.

28 Joaquín Costa, «Prólogo», en Antonio Royo Villanova, La Descentralización y el regionalismo..., op. cit. 
trado su derecho», y cerradas las vías de diálogo, acaba por «rebasar en su demanda el límite de lo justo, que antes le habría satisfecho», es decir, que no acepta pactos y «lo quiere todo». Así pues, pensaba que el gobierno centralista español al retener la autonomía que reivindicaban los antillanos, hizo que éstos tomasen «ya no la autonomía, sino la independencia. Y no es cosa de olvidar que los hombres de aquí no son de pasta diferente que los de Cuba, y que no faltan yankees en Europa». Si España se modernizaba, Costa pensaba que se inclinaría la «balanza del lado de la descentralización», pero si no se regeneraba el regionalismo se decantaría por la «separación, cuando no del anexionismo», ya que hartos de ser «otras tantas Cubas humilladas y explotadas, colonias de Madrid o de Barcelona, pedirán convertirse en otras tantas Argelias protegidas y bien gobernadas, colonias de Londres o París». ${ }^{29}$

A juicio de Costa, la monografía de Royo era trascendente y consideraba que el autor era, como también sus hermanos, «culto, discreto y equilibrado», con un gran sentido de la proporción, y dominio del objeto de su estudio. También resaltaba su «absoluta sinceridad», su perspicacia práctica, su talento de fino observador y con estas aptitudes el «joven profesor es una esperanza legítima para la ciencia española». En síntesis, Costa defendía que España podía redimirse, pero para conseguirlo era necesario agrupar a los «elementos intelectuales dispersos y juntarlos en una bien concertada unidad», en la que tendría un rol destacable Antonio Royo Villanova. ${ }^{30}$

En Valladolid inició su militancia política en el grupo liberal liderado por José Canalejas Méndez (1854-1912). Después del asesinato del dirigente liberal, se adscribió al grupo que dirigía Santiago Alba. Lo eligieron concejal, diputado a Cortes, senador y, en dos ocasiones, director general de primera enseñanza. ${ }^{31}$ No obstante, el partido liberal era el más centralista de los dos partidos dinásticos. En este período, el discurso político de Royo se caracterizaba por la defensa de la descentralización administrativa, la voluntad de universalizar la educación en todos sus grados, impulsar las obras públicas, el fomento de la agricultura para regenerar y modernizar España y por encima de todo «colocó siempre la unidad nacional como algo sagrado e intangible. En aras de estos ideales sacrificó su hacienda, expuso su vida y sufrió terribles penas y ataques sobremanera

${ }^{29}$ Ibídem.
30 Ibídem.
31 Ibídem y Luis Jordana de Pozas, «In Memoriam...», op. cit., p. 162.

Historia Contemporánea 51: 609-640 
injustos»..$^{32}$ Durante la II República, los catalanistas lo caricaturizaban como un personaje de limitada inteligencia, tozudo, clerical y monárquico. ${ }^{33}$

En 1908, en su libro El problema catalán mostraba las que serían sus señas de identidad a lo largo de toda su carrera política. Explicaba que había viajado a Barcelona de buena fe y con la intención de escribir un estudio imparcial sobre Solidaritat Catalana (S. C.). Quería saber si el amor de unos a la patria grande -España- y de los otros a la patria chica - Cataluña- «se les ha subido a la cabeza». ${ }^{34}$

S. C. se constituyó en febrero de 1906, tras el asalto de militares de la guarnición de Barcelona a las redacciones del diario La Veu de Catalunya y de la revista humorística $\mathrm{Cu}$-Cut! vinculadas a la Lliga Regionalista. La plataforma electoral integraba a la Lliga, la Unión Republicana, los federales, independientes, como el entonces teniente coronel Francesc Macià (1859-1933), los nacionalistas republicanos, la Unió Catalanista, los carlistas y los integristas católicos. No se integraron en S. C. los dirigentes catalanes de los dos principales partidos dinásticos - liberales y conservadores -, los republicanos liderados por Alejandro Lerroux (1864-1949) y las formaciones obreristas. En las elecciones de 1907 los candidatos solidarios se impusieron en casi todas las circunscripciones electorales catalanas. ${ }^{35}$

El movimiento que cuajó en S. C. exigía la retirada de la ley de Jurisdicciones, aprobada en marzo de 1906, que remitía a la jurisdicción militar cualquier ofensa a la unidad española, al honor de las fuerzas armadas y a sus símbolos. Sin embargo, a juicio de Royo, la plataforma electoral catalana respondería al hecho que Cataluña era la región española más industrializada, y Barcelona la ciudad más desarrollada, con lo que «no podía conformarse» con ser una provincia como el resto, ni en estar sometida a Madrid. Estaba convencido que los catalanistas pretenderían refundar España sobre la hegemonía catalana. ${ }^{36}$ También pensaba que se

${ }^{32}$ Luis Jordana de Pozas, «In Memoriam...», op. cit., p. 162.

33 Josep María Proas y Josep Bartolí, Auca de Royo Villanova [Document gràfic]: heus ací la vida trista d'un senyor separatista: aquesta auca dóna prova que hi ha en Royo Villanova, 1932?, http://mdc.cbuc.cat/cdm/ref/collection/pavellorepu/id/905. 4/2/2014. 10:41.

${ }^{34}$ Antonio Royo Villanova, El problema catalán. Impresiones de un viaje a Barcelona, Lib. de Victoriano Suárez, 1908, p. VIII-IX del prólogo. Véase también Ricardo Robledo Hernández, «L'actitud castellana...», op. cit., p. 228, especialmente en la nota 27, pp. 237-238, nota 52, y nota 62, pp. 240-241.

35 Gemma Rubí y Francesc Espinet (eds.), Solidaritat catalana i Espanya: (19051909), Base, Barcelona, 2008.

${ }^{36}$ Antonio Royo Villanova, El problema catalán..., op. cit., p. 5-6. 
trataba de una plataforma electoral esencialmente conservadora, y explicaba su triunfo electoral por su «significación antirrevolucionaria, antidemagógica, antianarquista». No le gustaba que Barcelona, que veía como la «mejor ciudad española, sienta tan poco afecto a España», pero entre la destrucción por los atentados anarquistas o «verla rica y floreciente, aunque no sea nuestra, iqué demonio!, yo no puedo dudar». ${ }^{37}$

No obstante, se oponía tajantemente al uso de la lengua catalana en el sistema educativo público ${ }^{38}$ ya que veía en el idioma castellano la síntesis del «espíritu patrio». En aquel período afirmaba que los españoles tenían una «fe en la unidad nacional» comparable al dogma católico de la Purísima Concepción. De hecho, durante la Restauración, el partido liberal en el que militaba Royo tenía una visión histórica de la nación española, entendida como entera y soberana. ${ }^{39}$ Sin embargo, la concepción de la nación de Royo basada en el idioma castellano, la idea de «espíritu patrio» y de la «fe» en la unidad nacional española remiten a un imaginario más bien ahistórico. No obstante, en el período en que vivió Royo Villanova la identificación a una perspectiva del nacionalismo histórico o ahistórico y, por tanto, antiliberal, era una cuestión de percepción, como se pone de manifiesto en su coetáneo el moravo Tomáš Masaryk. ${ }^{40}$

37 Ibídem, p. 16.

38 Ibídem,pp. 134 y 151.

39 Javier Moreno Luzón, «El españolismo de...», op. cit., pp. 584-585. Su perspectiva sobre el castellano la formuló en el artículo Antonio Royo Villanova, «La autonomía y el idioma», $A B C, 25$ de febrero de 1919. Artículo citado por Moreno Luzón en la p. 1320.

40 Andrea Orzoff, Battle for the Castle. The Myth of Czechoslovakia in Europe 19141948, Oxford University Press, Oxford, 2009, p. 33. De hecho, la evolución política de Royo Villanova desde el liberalismo de notables hacia posturas que pueden ser vistas como antiliberales, a través de un determinado discurso nacionalista no es solo una característica de su vida política o del caso español, es un fenómeno europeo del período de entreguerras. Así pues, es significativa la evolución de la Action Française de Charles Maurras, como se puede observar en los estudios de Stéphane Giocanti, Charles Maurras: el caos y el orden, Acantilado, Barcelona, 2010 o Robert Lynn Fuller, The Origins of the French Nationalist Movement, 1886-1914, McFarland \& Company, Jefferson/London, 2012. Véase también el artículo de Miguel Ángel Perfecto García, «La derecha radical española y el pensamiento antiliberal francés en el primer tercio del siglo Xx. De Charles Maurras a Georges Valois», Studia historica. Historia contemporánea, n. ${ }^{\circ}$ 30, 2012, pp. 47-94. La perspectiva europea del nacionalismo español ha sido ampliamente estudiada por Ismael Saz, «Regeneracionismos y nuevos nacionalismos. El caso español en una perspectiva europea», en Ismael Saz y Ferran Archilés, Estudios sobre nacionalismo y nación en la España contemporánea, Prensas Universitarias de Zaragoza, Zaragoza, 2011, pp. 55-78. 
Royo reconocía la «buena fe de los nacionalistas», cuando defendían que Cataluña era una nación, pero consideraba que estaban equivocados, ya que «no me cabe en la cabeza que Cataluña sea una nación, y creo, además, que no lo han demostrado los que tal cosa sostienen». Pensaba que los intelectuales «castellanos» tenían que discutir serenamente con los «catalanes», ya que así demostrarían que «no nos asustamos de nada» y que se podía «defender todo», pero con fundamento científico, y como tenía «fe en la ciencia y en la verdad» esperaba que el «nacionalismo desaparecerá», porque es una «preocupación y no una doctrina; porque como dijo Hegel, todo lo racional es real y viceversa, y por eso la nación catalana no es racional porque no es real y no es real, porque no es racional». ${ }^{41}$

Cuando se iniciaba la segunda década del siglo Xx le nombraron diputado por el partido liberal por la circunscripción de Valderrobres (o Vallde-Roures) Teruel, sustituyendo al también aragonés Manuel Sastrón y Piñol en enero de 1912. Le eligieron diputado por la circunscripción turolense en 1916 y mantuvo el escaño hasta 1918; en ese período argumentaba que los parlamentarios catalanistas utilizaban un doble discurso, de un lado, moderado y pactista en el Congreso y, del otro, el que él identificaba como verdadero ante sus electores. ${ }^{42}$ Le eligieron senador por Valladolid en 1914, por Huelva en 1919 y por Teruel en 1921, hasta que el 2 de junio de 1923 fue designado senador vitalicio. ${ }^{43}$

Fue nombrado director general de primera enseñanza, en octubre de 1913, a las órdenes del ministro de Instrucción Pública, Joaquín Ruiz Giménez (1854-1934), en el seno del Gobierno presidido por Álvaro de Figueroa y Torres, conde de Romanones (1863-1950). Ocupó el cargo una semana, y presentó su renuncia cuando el ejecutivo liberal fue substituido por uno de conservador, ${ }^{44}$ pero, en diciembre de 1915 , cuando Romanones recuperó el control del ejecutivo, Royo volvió a ser nombrado director general de primera enseñanza, y en esta ocasión mantuvo el cargo hasta junio de 1917. Sus partidarios aseguraban que Romanones «no se atrevió a

41 Antonio Royo Villanova, El problema catalán..., op. cit., pp. 169, 176 y 185.

42 Ricardo Robledo Hernández, «L'actitud castellana...», op. cit., p. 240.

${ }^{43}$ Luis Teófilo Gil Cuadrado, «Antonio Royo-Villanova: el centralismo liberal en la II República», en José Luis Casas Sánchez y Francisco Durán Alcalá (coords.), Historia y biografía en la España del siglo Xx: II Congreso sobre el Republicanismo, Patronato «Niceto Alcalá-Zamora y Torres», Priego de Córdoba, 2003, p. 391.

${ }^{44}$ http://www.filosofia.org/ave/001/a333.htm. 5/2/2014. 18:14. 
incluir a Royo-Villanova en ninguno de sus Gobiernos, por lo mucho que se había significado el catedrático en sus ataques contra el separatismo catalán». ${ }^{45}$ En ese período, la prensa republicana catalana ya lo identifica como uno de los principales anticatalanistas. ${ }^{46}$

En 1910, publicó una amplia monografía, en Valladolid, sobre la problemática obrera en España titulada Cuestiones obreras, ${ }^{47}$ con un prólogo de Gumersindo de Azcárate (1840-1917). Éste era un dirigente republicano, jurista, historiador, fundador de la Institución Libre de Enseñanza, presidente del Instituto de Reforma Social e impulsor de la Sociología en España. En 1914, también editaron su discurso de apertura del curso de la Universidad de Valladolid, sobre la descentralización española. ${ }^{48}$ Tampoco abandonó su preocupación por la descentralización municipal, en obras como Las haciendas locales, publicada en Zaragoza, en 1915.

Royo era consciente que la constitución de la Mancomunidad catalana, en 1914 bajo la dirección de Enric Prat de la Riba (1870-1917), ${ }^{49}$ era un gran cambio para la administración española. Consideraba positivo el proceso descentralizador, pero lo que le preocupaba, tal como explicó el 12 de enero de 1917, en la Real Academia de Jurisprudencia y Legislación, era la consolidación del nacionalismo catalán, pues consideraba que para conseguir diferenciar a los catalanes del resto de los españoles e impulsar las reivindicaciones catalanistas «había que abrir un abismo por medio del odio, y esto lo reconoce Prat de la Riba», al defender que Cata-

45 S. A. «Anecdotario de Don Antonio Royo Villanova», $A B C, 12 / 11 / 1958$, p. 65.

46 Véase las caricaturas reproducidas en la portada de la revista: Jaume Passarell, «Plat del dia. El català. Si és servit!...», L'Esquella de la Torratxa. Periòdic humorístic il·lustrat, n. ${ }^{\circ} 1931,30 / 12 / 1915$, p. 865 y S. A. «Els lladrucs del anticatalanisme», L'Esquella..., op. cit., n. ${ }^{\circ} 1986,19 / 1 / 1917$, p. 49.

47 Antonio Royo Villanova, Cuestiones obreras, Imprenta Castellana, Valladolid, 1910.

48 Antonio Royo Villanova, La nueva descentralización. Discurso leído en la Universidad de Valladolid en la inauguración del curso de 1914 a 1915, Valladolid, 1914.

49 Enric Ucelay-Da Cal, El imperialismo catalán..., op. cit., pp. 448-454, y del mismo autor La Catalunya populista. Imatge, cultura i política a l'etapa republicana (1931-1939), La Magrana, Barcelona, 1982. Josep R. Llobera, «La formación de la ideología nacionalista catalana», L'Avenç, n. ${ }^{\circ}$ 63, 1983, pp. 24-35. Patrizio Rigobon, «Enric Prat de la Riba: la ideología del pragmatismo nacionalista catalán», Spagna Contemporánea, n. ${ }^{\circ}$ 1, 1992, pp. 25-48. Josep María Ainaud de Lasarte, Prat de la Riba, Edicions 62, Barcelona, 1992. 
luña era una nación, y «como no puede haber dos naciones distintas, Cataluña no es España, y los catalanes no son españoles». ${ }^{50}$

Le preocupaba tanto la consolidación del catalanismo que aprendió el catalán -idioma que se habla en el municipio del que era oriundo su padre - y tradujo al castellano La nacionalitat catalana. Consideraba que Prat de la Riba era el «verdadero maestro de los intelectuales catalanistas», y el propagador de la idea que España no era una nación, sino un Estado, con lo que vendría a ser una expresión geográfica que de la mano de Castilla habría intentado absorber a la mayor parte de las nacionalidades ibéricas. También aseguraba que los catalanistas defendían que se reconociese su nacionalidad y, posteriormente, «su constitución en un Estado propio, distinto del Estado español». ${ }^{51}$

A pesar de las discrepancias ideológicas, se esforzaba por presentarse optimista de cara a un futuro acercamiento de posiciones entre los nacionalismos español y catalán, aunque reconocía que no encontraba la manera, pero confiaba en el supuesto ciclo histórico, en que «primero, se combaten, luego se conocen y acaban por amarse fundiéndose en una comunidad espiritual de justicia y de cultura». ${ }^{52}$ Sin embargo, sus supuestas buenas intenciones eran de difícil concreción, ya que Royo se enconó en un anticatalanismo radical y vehemente, ${ }^{53}$ hasta el punto que tal como explicaba el periodista, escritor y humorista Wenceslao Fernández Flórez (1885-1964), cuando algún catalanista hablaba en las Cortes, «Royo se agitaba impacientemente, gruñía, hacía girar los ojos de una feroz manera, interrumpía, pedía la palabra, golpeaba con su bastón en el pupitre». Se opuso tajantemente al proyecto de Estatuto de autonomía catalán impulsado por la Lliga Regionalista, entre 1918 y 1919. Una propuesta que

50 Antonio Royo Villanova, Conferencia del Ilmo. Señor D. Antonio Royo Villanova pronunciada en la sesión pública de 12 de enero de 1917. Tema: Las bases doctrinales del nacionalismo, Establecimiento tipográfico de Jaime Ratés, Madrid, 1917, pp. 6-7.

51 Antonio Royo Villanova, prólogo en Enric Prat de la Riba, La nacionalidad catalana, Imprenta Castellana, Valladolid, 1917, pp. 13. Encontraran una copia digital en http://bvpb.mcu.es/es/consulta/registro.cmd?control=BVPB20110107239. 6/2/2014: 10:28.

52 Ibídem, p. 35. Véase también Ricardo Robledo Hernández, «L’actitud castellana...», op. cit., pp. 240-241, nota 62, y Javier Moreno Luzón, «El españolismo de...», op. cit., p. 590.

53 Antonio Royo Villanova, «Los peligros del nacionalismo. Al maestro Azorín», El Norte de Castilla, 16 de diciembre de 1918. Citado por Ricardo Robledo Hernández, «L'actitud castellana...», op. cit., p. 242. 
generó una «marea españolista» en la que Royo Villanova participó activamente. ${ }^{54}$

En 1918, cuando estaba finalizando la Primera Guerra Mundial, pronunció otra conferencia en el Ateneo de Madrid sobre el nacionalismo catalán y la política internacional, ${ }^{55}$ para denunciar que, desde su perspectiva, algunos catalanistas radicales interferían en la actividad diplomática española. En 1919, le publicaron dos conferencias, la primera de temática administrativista vinculada a la descentralización municipal que se asemejaría a la regional, pero se caracterizaría por una menor intensidad ${ }^{56}$ mientras que en la segunda reivindicaba el papel de los militares en la educación de los españoles. ${ }^{57}$

En este período, expuso su visión sobre la actividad sindicalista y la revolución comunista que había triunfado en Rusia y que había afectado a diversos países europeos, en una conferencia pronunciada el 20 de diciembre de 1919, pero que publicaron en $1920 .{ }^{58}$ Royo ingresó en la Real Academia de Ciencias Morales y Políticas, el 27 de noviembre de 1921, con un discurso sobre el terrorismo - que afectaba principalmente a Barcelona-, las libertades que garantizaba el sistema jurídico constitucional español y la actividad policial..$^{59} \mathrm{El}$ discurso fue contestado por el entonces dirigente liberal, jurista y académico Niceto Alcalá Zamora (18771949)..$^{60}$

${ }^{54}$ Citado por Javier Moreno Luzón, «El españolismo de...», p. 590 y las referencias a la campaña antiautonómica en las pp. 593-594. Sobre la propuesta autonómica catalanista véase David Martínez Fiol, El catalanisme i la Gran Guerra, La Magrana, Barcelona, 1988; Albert Balcells, Enric Pujol y Jordi Sabater, La Mancomunitat de Catalunya i l'autonomia, Institut d'Estudis Catalans, Barcelona, 1996; Albert Balcells, El projecte d'autonomia de la Mancomunitat i el seu context històric, Parlament de Catalunya, Barcelona 2010.

55 Antonio Royo Villanova, El nacionalismo regionalista y la política internacional de España, Imprenta de Justo Martínez, Madrid, 1918.

56 Antonio Royo Villanova, La autonomía y la municipalización. Conferencia del 10 de Abril de 1919, Imprenta Municipal, Madrid, 1919.

57 Antonio Royo Villanova, La misión educativa del Ejército. Conferencia pronunciada el 26 de abril de 1919, Centro del Ejército y de la Armada, Madrid, 1919.

58 Antonio Royo Villanova, Bolchevismo y sindicalismo, Editorial Reus, Madrid, 1920.

59 Antonio Royo Villanova, El terrorismo, la libertad y la policía. Discurso de ingreso, Real Academia de Ciencias Morales y Políticas, Madrid, 1921.

60 Niceto Alcalá Zamora, Contestación del Excmo. Señor D. Niceto Alcalá Zamora, el día 27 de noviembre de 1921, RACMP, Madrid 1921. Se puede consultar en formato pdf en http://www.racmyp.es/actividades/HOMENAJES.CFM?ac=list\&an=H9. 6/3/2014. 12:07. 
Royo fue plenamente consciente de la importancia de la derrota en Annual, en julio de 1921, en el conflicto que enfrentaba a las tropas españolas con las cabilas rifeñas, tal como explicó en la conferencia que pronunció el 10 de diciembre de 1921, ante las Juventudes de la Izquierda Liberal. ${ }^{61}$

La crisis generada por la debacle militar en el Norte de África y la inestabilidad interna por la gran actividad terrorista que afectaba España, con su principal foco en Barcelona, posibilitaron el cambio de régimen de la mano del general Primo de Rivera (1870-1930). ${ }^{62}$ Durante los años de la primera dictadura española del siglo Xx, Royo no colaboró con la misma, aunque algunos de los defensores de la dictadura afirmaban que eran regeneracionistas y que uno de sus referentes sería el costismo.

En este período, recuperó su actividad docente y utilizó la libertad de cátedra para criticar la censura establecida por el régimen dictatorial. Desde su perspectiva, era preferible la supresión del Parlamento, de la responsabilidad ministerial, del habeas corpus o del control presupuestario, que la supresión de la libertad de la prensa, «porque esa libertad, tarde o temprano, por sí sola, se basta para devolvernos todas las demás». ${ }^{63}$ No obstante, se daba la paradoja que consideraba necesaria la Ley de Jurisdicciones, aunque ésta limitaba substancialmente la libertad de expresión. Sus críticas implicaron que le abriesen un expediente, con lo que podría haber perdido su cátedra. Los catalanistas afirmaban que en el inicio de la dictadura habría intentado conseguir el beneplácito de Primo de Rivera. No lo logró y para no aburrirse habría recuperado su actividad académica y anticatalanista.$^{64}$ Durante el período dictatorial, no se adhirió al republicanismo, porque lo vinculaba al desorden, la intranquilidad y el separatismo. ${ }^{65}$

61 Antonio Royo Villanova, El problema de Marruecos y la politica liberal. Conferencia pronunciada el 10 de diciembre de 1921, Juventud de la Izquierda Liberal, Madrid 1922.

62 Alejandro Quiroga Fernández de Soto, «Cirujano de Hierro. La construcción carismática del general Primo de Rivera», Ayer, n. ${ }^{\circ}$ 91, 2013, pp. 147-168.

${ }^{63} \mathrm{http}: / /$ canales elnortedecastilla.es/150aniversario2/especial/1937empresa.html. 6/2/2014, 12:33.

64 J.M. Prous y J. Bartolí, Auca de Royo..., op. cit.

65 Luis Teófilo Gil Cuadrado, «Antonio Royo-Villanova...», op. cit., p. 392. 
En estos años publicó su Programa de Derecho Administrativo ${ }^{66}$ Escribió un artículo en la Revista general de legislación y jurisprudencia sobre el Estatuto Municipal, ${ }^{67}$ y sobre el pensamiento jurídico del líder conservador Antonio Cánovas del Castillo (1828-1897). ${ }^{68}$ En 1929, publicó un estudio sobre el derecho público español en el período de la Regencia de María Cristina, ${ }^{69}$ y como académico honorario de la Academia de Jurisprudencia dedicó una conferencia al dirigente liberal Segismundo Moret (1833-1913), en la que aseguró que era el verdadero fundador del Instituto de Reformas Sociales y en la que argumentó que la ley de jurisdicciones, aprobada cuando presidía el ejecutivo Moret, era una «necesidad de Gobierno». ${ }^{70}$ Finalmente, después del período de transición de la dictablanda retomó su actividad política.

\section{Un grito contra el Estatuto. Por la nación única}

Las elecciones municipales del 12 de abril de 1931 pusieron de manifiesto que una parte substancial de la población española no quería volver al sistema político anterior a la dictadura de Primo, y que era partidaria de instaurar la República. El 14 de abril de 1931, Lluís Companys (1882-1940), uno de los dirigentes de Esquerra Republicana de Cataluña (ERC), proclamó la República Federal española, desde el balcón del Ayuntamiento de Barcelona. Posteriormente, Francesc Macià, el principal líder de ERC, que era un partido con múltiples tendencias, proclamó la: «República Catalana com a Estat integrant de la Federació ibèrica», ${ }^{71}$ mientras en Madrid anunciaban el inicio de la segunda República.

66 Antonio Royo Villanova, Programa de Derecho Administrativo, Imprenta Castellana Valladolid, 1926 y 1929.

67 Antonio Royo Villanova, «El Estatuto Municipal y la libertad de los Ayuntamientos», Revista general de legislación y jurisprudencia, n. ${ }^{\circ}$ 150, p. 1927.

68 Antonio Royo Villanova, Las ideas jurídicas de don Antonio Cánovas del Castillo, Tip. La Académica, Zaragoza, 1928.

69 Antonio Royo Villanova, La Regencia y el Derecho público español. Homenaje a la Reina Doña María Cristina, Editorial Reus, Madrid, 1929.

70 S. A., «En la Academia de Jurisprudencia. "Moret"», $A B C, 30 / 4 / 1930$, p. 23. http://hemeroteca.abc.es/nav/Navigate.exe/hemeroteca/madrid/abc/1930/04/30/023.html. 6/2/2014. 14:51.

71 Dolors Ivern i Salvà, Esquerra Republicana de Catalunya (1931-1936), vol. I, Publicacions de 1'Abadia de Montserrat, Barcelona, pp. 91-102. Véase también Joan B. Culla, Esquerra Republicana de Catalunya 1931-2012, La Campana, Barcelona, 2013. 
El 17 de abril, Macià formó el Gobierno de la República catalana, aunque fue efímero, pues el mismo día el Gobierno Provisional, que encabezaba Niceto Alcalá-Zamora, envió a tres ministros - Fernando de los Ríos, Marcelino Domingo y Lluís Nicolau d'Olwer - para tratar de resolver el conflicto. Éste se solucionó acordando que se disolviese la Republica catalana, pero que se iniciase el proceso para redactar el Estatuto autonómico catalán, cuando aún no se había iniciado el proceso para redactar la Constitución, y el reconocimiento de la Generalitat de Cataluña, como gobierno autonómico provisional. ${ }^{72}$

Royo afirmaba que la actuación del gobierno español había sido «vergonzosa», ya que pensaba que la actitud correcta habría sido «aplastar la rebeldía, como hicieron en 1873 Pi y Margall, Salmerón y Castelar con la insurrección cantonal». ${ }^{73}$ Estaba convencido que Macià había cedido, porque «no tenía fuerza para seguir manteniendo su independencia; si hubiera tenido fuerza, hubiera proclamado la República independiente». ${ }^{74}$

Con vistas a la elaboración del anteproyecto de Estatuto de autonomía, la Generalitat provisional nombró una ponencia redactora presidida por Jaume Carner (1867-1934) que, reunida en el Valle de Núria (en el Pirineo catalán), redactó el primer proyecto de Estatuto, el 20 de junio de 1931. El llamado Estatuto de Núria fue aprobado por la mayor parte de los municipios catalanes y sometido a referéndum en Cataluña, el 2 de agosto de 1931, obteniendo un amplio apoyo popular. ${ }^{75}$

En este período, Royo se presentó como candidato independiente, pero vinculado a los agrarios, por Valladolid, en las elecciones a Cortes Constituyentes celebradas el 28 de junio de $1931 .^{76}$ Las preocupaciones fundamentales de los agrarios eran defender la religión católica, el cen-

72 Manuel Gerpe, L'Estatut d'autonomia i l'Estat integral, Edicions 62, Barcelona, 1977, pp. 235-239.

${ }^{73}$ Antonio Royo Villanova, Treinta años de política antiespañola, Santarén, Valladolid, 1940, p. 118.

${ }^{74}$ Ibídem, p. 138. Luis Teófilo Gil Cuadrado, «Antonio Royo-Villanova...», op. cit., pp. 394-395 y del mismo autor, El Partido Agrario español (1934-1936): Una alternativa conservadora y republicana, tesis dirigida por Octavio Ruiz Manjón, Universidad Complutense de Madrid, Madrid, 2006, p. 182.

75 Manuel Gerpe, L'Estatut..., op. cit., p. 289.

76 M.T. Gutiérrez Rodríguez, «Perfil y trayectoria...», op. cit., pp. 598-601. Luis Teófilo Gil Cuadrado, «Antonio Royo-Villanova...», op. cit., pp. 392-393 y del mismo autor El Partido Agrario...., op. cit., pp. 119-203. 
tralismo político, la familia tradicional, el control estatal del sistema educativo y la defensa de la propiedad privada. Obtuvieron 23 diputados, entre los que sobresalían José Martínez de Velasco (1875-1936) y Royo Villanova. De hecho, tenían una concepción política y social muy parecida a la de los diputados de la minoría vasco-navarra, excepto en la cuestión autonómica, ya que «los agrarios eran centralistas, sobre todo Antonio Royo Villanova». ${ }^{77}$

En las Cortes Constituyentes, Royo participó con «extraordinario ímpetu y preparación en los debates sobre la Constitución Republicana, el Estatuto de Cataluña y la Ley municipal» ${ }^{78}$ En cuanto a la organización territorial, sobresalió por su intransigencia. Ésta se puso de manifiesto al solicitar que en el Título Preliminar del texto constitucional se substituyera España por nación española y se identificara al Estado como la «soberana expresión jurídica de una solidaridad económica y espiritual», ${ }^{79}$ pues lo contrario podría ser interpretado como una concesión a los que identificaba como nacionalistas, aunque el discurso de Royo era de un acendrado nacionalismo, en su caso, español.

El anteproyecto de Estatuto redactado en Núria daba por sentado que España se organizaría como un Estado federal, en el que Cataluña sería, tal como decía su primer artículo: «un Estat autònom dintre la República espanyola». También acordaron que el catalán sería la lengua oficial de Cataluña. Se establecía una clara distribución de competencias entre el gobierno central y la Generalitat, en la que a ésta le correspondería la enseñanza, el régimen municipal y la división territorial interna, el derecho civil e hipotecario, la organización judicial, las obras públicas, el asistencialismo, la legislación agropecuaria y el orden público del Estado autónomo. Las competencias compartidas con el Gobierno central se centraban especialmente en el ámbito fiscal y hacendístico. Las competencias ejecutivas las ejercería la Generalitat, encabezada por un presidente, las legislativas, el Parlamento, y las judiciales, el Tribu-

77 José Luis de la Granja Sáinz, Nacionalismo y II República en el País Vasco. Estatutos de Autonomía, partidos y elecciones. Historia de Acción Nacionalista Vasca: 19301936, Madrid, Siglo XXI, 2009, p. 262.

${ }^{78}$ Luis Teófilo Gil Cuadrado, El Partido Agrario..., op. cit., p. 162.

79 Ibídem, p. 130, y del mismo autor, «Antonio Royo-Villanova...», op. cit., pp. 392-393. Véase también Santos Juliá, «Nación, nacionalidades y regiones en la transición política a la democracia», en Antonio Morales Moya, Juan Pablo Fusi Aizpurúa y Andrés de Blas Guerrero (dirs.), Historia de la nación ..., op. cit., p. 887. 
nal Superior de Justicia de Cataluña. El presupuesto provendría de los fondos de las diputaciones provinciales catalanas, así como de los impuestos y tasas vinculados a las competencias que establecía el Estatuto de autonomía. ${ }^{80}$

Entre los meses de enero y de abril de 1932, la Comisión de Estatutos de las Cortes, de la que Royo formaba parte, adecuó el Estatuto de Núria a la Constitución aprobada el 9 de diciembre de 1931. El 8 de abril, la Comisión presentó su dictamen, en el que suprimía los puntos del proyecto estatutario catalán que chocaban con la nueva norma básica de la República. El anteproyecto quedó reducido substancialmente, ya que Cataluña pasaba de Estado autónomo a región autónoma, establecían el bilingüismo, reducían casi todas las competencias legislativas, y muchas de las ejecutivas. Además, el Gobierno central podía intervenir en las materias ejercidas por la Generalitat, sin requerimiento del Gobierno autónomo. ${ }^{81}$ No obstante, Royo afirmaba que las Cortes Constituyentes no habrían tenido otra misión que «votar el Estatuto de Cataluña; la misma Constitución no fue más que un simple prólogo o un modesto andamiaje para construir el famoso Estatuto, fuente y raíz de todos los males de España». ${ }^{82}$

En 1934, publicó sus comentarios a la Constitución de 1931, en los que reconocía que su actuación en las Cortes Constituyentes se centró en defender el Concordato entre España y el Vaticano, y en oponerse a la descentralización política de España, ya que se declaró «francamente unitario y resueltamente antifederalista». 83

El 6 mayo de 1932, se iniciaron los debates parlamentarios sobre el Estatuto catalán en las Cortes Constituyentes. Los catalanistas recordaban que Royo dedicó todas sus energías a intentar hacer abortar el proyecto de Estatuto de Autonomía o, en su defecto, reducir todo lo que estuviese vinculado con la descentralización política y educativa. Utilizó toda su experiencia ju-

${ }^{80}$ Isidre Molas, El sistema de partits polítics a Catalunya (1931-1936), Edicions 62, Barcelona, 1972. José Antonio González Casanova, Federalisme i autonomia a Catalunya (1868-1938), Curial, Barcelona, 1974. Manuel Gerpe, L'Estatut..., op. cit. Josep María Roig i Rosich, L'Estatut de Catalunya a les Corts constituents (1932), Curial, Barcelona, 2006. Enric Ucelay-Da Cal, La Catalunya populista...op. cit. Teresa Abelló, El debat estatutari del 1932, Parlament de Catalunya, Barcelona, 2007.

${ }^{81}$ Luis Teófilo Gil Cuadrado, El Partido Agrario...op. cit., pp. 151-171.

82 Antonio Royo Villanova, Treinta años de política...op . cit., p. 135.

${ }^{83}$ Antonio Royo Villanova, La Constitución española de 9 de diciembre de 1931 con glosas políticas y apostillas políticas, Imprenta Castellana, Valladolid, 1934, p. 10. 
rídica, docente y política, para intentar boicotear la aprobación de la autonomía catalana. Las publicaciones catalanistas comenzaban a caracterizarlo como un asno tozudo, o como un payaso parlamentario que odiaba Cataluña. Lideró la obstrucción sistemática del anteproyecto de Estatuto catalán, a través de presentaciones de múltiple enmiendas, discursos largos, virulentos y votaciones nominales con lo que armaba siempre un «gran trasbals». ${ }^{84}$

Diego Martínez Barrio (1883-1962) veía a Royo como al «gran inquisidor del patriotismo intransigente». Era el «guardián honorario del sepulcro de Carlos I» y en nombre de $s u$ España, «luchaba contra todos». Trazó una línea divisoria entre «españoles auténticos, de los que era capitán y adelantado, y los egoístas sin patria». Los primeros eran heroicos, bravos y mostraban su «amor a la nación, una e indivisible». Los segundos se caracterizarían por su «sevicia, la claudicación y la cobardía». Su objetivo sería que los militares abortasen la autonomía catalana y la descentralización política con un golpe de Estado. ${ }^{85}$

La intransigencia de Royo frente a cualquier tipo de legislación autonomista fue en aumento durante el debate parlamentario. Llegó a sostener que con cada artículo que aprobasen «aumentará la vergüenza de unos diputados traidores», o que el castellano «no necesita, en verdad, de Cataluña. Hay muchos pueblos que lo hablan allende los mares. Lo de menos en esto del Estatuto es el idioma. Los catalanes no quieren nuestro idioma; quieren nuestro dinero». ${ }^{86}$

En relación a la cuestión de la enseñanza, aseguró que los niños catalanes serían educados en la negación de la idea de España ${ }^{87}$ Era partidario que la Universidad de Barcelona siguiera dependiendo del Estado, pues una Universidad controlada por la Generalitat estaría amenazada de «esterilidad científica». Finalmente, el artículo séptimo del Estatuto con-

${ }^{84}$ Josep M. ${ }^{\text {a }}$ Prous y Josep Bartolí, Auca de Royo..., op. cit. Véase también Luis Teófilo Gil Cuadrado «Antonio Royo-Villanova...», op. cit., p. 394 y 398-399. Véase también, Antonio Royo Villanova, Diario de Sesiones del Congreso de los Diputados, debate sobre el Estatuto Catalán, 26 de mayo de 1932, pp. 5.824-5.825.

85 Diego Martínez Barrio, Memorias, Planeta, Barcelona, 1983, p. 130. Juan Simeón Vidarte, Las Cortes Constituyentes de 1931-1933. Testimonio del primer secretario del Congreso de Diputados, Grijalbo, Barcelona, 1976, p. 468. Véase también Luis Teófilo Gil Cuadrado, «Antonio Royo-Villanova...», op. cit., p. 398. Ricardo Robledo Hernández, «L'actitud castellana...», op. cit., pp. 246-248.

86 S. A., El Sol, 28/6/1932, p. 4.

87 Antonio Royo Villanova Treinta años de política...op. cit., p. 151. Véase también Luis Teófilo Gil Cuadrado, «Antonio Royo-Villanova...», op. cit., p. 395. 
signó la posibilidad de que la Generalitat fundara centros docentes, con independencia de los mantenidos por el Estado, y que la Universidad de Barcelona fuese regida por un Patronato autónomo que garantizase el uso de las lenguas castellana y catalana en el ámbito universitario. ${ }^{88} \mathrm{El}$ artículo fue aprobado por 129 votos a favor y 84 en contra. No obstante, Royo afirmaba que los nacionalistas catalanes no ejecutarían con lealtad las leyes españolas, y defendía que la legislación estatal la aplicasen funcionarios españoles, con lo que implícitamente el catedrático en Derecho Administrativo argumentaba que la administración de la Generalitat no sería española. ${ }^{89}$

Entre los adversarios a la autonomía catalana destacaban intelectuales de la talla de José Ortega y Gasset (1883-1955) o de Miguel de Unamuno y Jugo (1864-1936). Sin embargo, éstos tenían un cierto prestigio intelectual entre los catalanistas. En cambio, en Royo veían un filibustero parlamentario. La tensión llegó a ser tan grande que el diputado de ERC «[Joan] Puig i Ferreter [(1882-1956)], molt viu, li diu iiiRUC!!! i tothom riu». ${ }^{90}$ Royo acusaba a los catalanistas de perjudicar las relaciones exteriores de la República española y les reprochaba su supuesto egoísmo, ya que «vosotros sois catalanes antes que republicanos». 91

De manera paralela a la discusión parlamentaria, los partidarios del centralismo promovieron una dura campaña contra el Estatuto, con actos públicos, que iban desde mítines a manifestaciones, y con una campaña periodística, impulsada principalmente por el $A B C, E l$ Imparcial y El Norte de Castilla, éste último era el principal portavoz de Royo. ${ }^{92} \mathrm{Su}$ actividad contraria al Estatuto catalán implicó que le organizasen una campaña de homenaje y de adhesión, en la que el acto más relevante fue el gran mitin en la plaza de toros madrileña, el 27 de julio de 1932, en el que se definió como un continuador de la tradición liberal decimo-

88 Albert Balcells, Cataluña ante España. Los diálogos entre intelectuales catalanes y castellanos (1888-1984), Editorial Milenio, Lleida, 2011, pp. 88-89.

${ }^{89}$ Intervención de Antonio Royo Villanova en las Cortes el 24 de junio de 1932, citado en Luis Teófilo Gil Cuadrado El Partido Agrario...op. cit., pp. 210-211, 213 y 215.

90 Josep María Prous y Josep Bartolí, Auca de Royo..., op. cit. Véase también Antonio Royo Villanova, Treinta años de política..., op. cit., p. 117; Luis Teófilo Gil Cuadrado, «Antonio Royo-Villanova...», op. cit., p. 394, nota 11, y El Partido Agrario op. cit., p. 107.

${ }_{91}$ Luis Teófilo Gil Cuadrado, «Antonio Royo-Villanova...», op. cit., p. 395.

92 Ibídem, p. 397. Véase también Ricardo Robledo Hernández, «L'actitud castellana...», op. cit., pp. 248-249. 
nónica, lanzó duras acusaciones hacia los catalanistas, e incitó a boicotear los productos catalanes. ${ }^{93}$ En la auca que le hicieron sus rivales catalanistas aseguraban que «se'n va a la plaça de braus a fer un "míting" als gripaus», en el que los reunidos lo consideraban un «gran español», mientras gritaban «muera el Estatuto». El homenajeado salió de la plaza a hombros. ${ }^{94}$

El 10 de agosto de 1932, el fracaso del golpe militar encabezado por el general José Sanjurjo (1872-1936) aceleró el debate sobre el Estatuto catalán y la reforma agraria. Royo finalizó sus tácticas obstruccionistas, pero siguió manteniendo su oposición a la autonomía catalana. ${ }^{95} \mathrm{Sin}$ embargo, para sorpresa del mismo Manuel Azaña (1880-1940), cuando finalmente aprobaron el Estatuto le felicitó de «corazón su antiguo amigo del Ateneo, don Antonio Royo Villanova, anticatalanista furibundo». ${ }^{96}$

Tras la aprobación del Estatuto de Autonomía, una buena parte de los catalanistas estaban satisfechos, a pesar de los sustanciales recortes, porque sabían que el intento de golpe de Estado militar pretendía abortarlo, y recordaban la magnitud de la campaña antiestatutaria que había tenido como uno de sus principales líderes a Royo, hasta el punto que en la auca anteriormente citada concluían que la aprobación del Estatuto implicaría la muerte política de Royo. ${ }^{97}$ Se equivocaron.

Royo mantuvo sus críticas a los catalanistas, tanto a los dirigidos por el progresista Francesc Macià, como a los liderados por el conservador Francesc Cambó (1876-1947), a quien acusó de ser «más peligroso porque es más inteligente, más astuto y tiene más cara de judío». ${ }^{98}$ Escribió

${ }_{93}$ M.T. Gutiérrez Rodríguez, «Perfil y trayectoria...», op. cit., pp. 601-604 y Luis Teófilo Gil Cuadrado, «Antonio Royo-Villanova...», op . cit., pp. 396-397.

94 Josep María Prous y Josep Bartolí, Auca de Royo..., op. cit.

95 Luis Teófilo Gil Cuadrado, «Antonio Royo-Villanova...», op. cit., p. 399 y El Partido Agrario...op. cit., p. 230.

96 Cipriano Rivas Cherif, Retrato de un desconocido. Vida de Manuel Azaña, Grijalbo, Barcelona, 1981, p. 249.

97 Sobre las intervenciones de Azaña en el debate autonómico Ricardo García Cárcel, La herencia del pasado. Las memorias históricas de España, Galaxia Gutenberg, Barcelona, 2011, pp. 341-346; Santos Juliá, Vida y tiempo de Manuel Azaña (1880-1940), Taurus, Madrid, 2008, pp. 301-321. Josep Contreras, Manuel Azaña y Cataluña. Historia de un desencuentro, Edhasa, Barcelona, 2008, pp. 172-181. Los textos del Auca se encuentran en Josep María Prous y Josep Bartolí, Auca de Royo..., op. cit.

98 S. A., El Debate, 14/11/1933 citado en Luis Teófilo Gil Cuadrado, El Partido Agrario..., op. cit., p. 271. 
unas glosas sobre la Constitución de $1931^{99}$ y un trabajo sobre Vázquez de Menchaca. ${ }^{100}$ Continuó su campaña antiautonomista, en actos como la conferencia del 9 de diciembre de 1932, en la que reconocía que el Estatuto no hacía peligrar la unidad española, pero se negó a aceptar la existencia de la nación catalana, ya que la unidad española se habría forjado con la conquista romana. ${ }^{101}$ También se mostró muy crítico con Largo Caballero (1869-1946) y sus iniciativas ministeriales, ya que era partidario de suprimir el ministerio de Trabajo; un Royo Villanova que era un «peso pesado de la intelligentsia de la derecha antirrepublicana española (...) la más enconada, si cabe, y de mucha brillantez polémica». ${ }^{102}$ En este período, publicó la recopilación de sus discursos y de sus artículos en contra del Estatuto, en un libro que tituló: Un grito contra el Estatuto. Por la nación única. ${ }^{103}$

\section{Anticatalanismo visceral, ministerio y ocaso}

La popularidad que adquirió Royo a través de su campaña en contra de la autonomía catalana le facilitó la reelección, en las elecciones generales de noviembre de $1933 .{ }^{104}$ En la nueva singladura parlamentaria, denunció que en Cataluña se incumplían los artículos de la Constitución que establecían que el castellano era el idioma oficial de la República y el predominio del Estado en materia educativa. ${ }^{105}$ Continuó acusando a los partidarios de la autonomía de defender un «odioso separatismo», y fue uno de los parlamentarios más críticos con el proyecto de Estatuto de autonomía vasco. ${ }^{106}$

99 Antonio Royo Villanova, La Constitución española..., op. cit., p. 25.

100 Antonio Royo Villanova, Vázquez de Menchaca y el Derecho de Gentes, Anuario de la Asociación Francisco de Vitoria, Madrid, 1933.

101 S. A., El Debate, 10/12/1932 citado en Luis Teófilo Gil Cuadrado, El Partido Agrario...op. cit., p. 232.

102 Julio Arostegui, Largo Caballero. El tesón y la quimera, Barcelona, Debate, 2013, pp. 285-288.

${ }^{103}$ Antonio Royo Villanova, Un grito contra el Estatuto. Por la nación única, Sociedad Administrativa de Ediciones Literarias, Madrid, 1932.

104 M.T. Gutiérrez Rodríguez, «Perfil y trayectoria...», op. cit., pp. 604-606 y Luis Teófilo Gil Cuadrado, «Antonio Royo-Villanova...», op. cit., p. 399.

${ }_{105}$ Luis Teófilo Gil Cuadrado, El Partido Agrario..., op. cit., p. 325.

106 José Luis de la Granja Sáinz, Nacionalismo y II República..., op. cit., pp. 383, 492-493 y 495 . 
En noviembre de 1933, en un banquete organizado en su honor aseguró que no había sido ministro durante la monarquía, ni en el período republicano por ser anticatalanista. Afirmó que dedicaría todas sus energías a liberar a los presos por la insurrección de 1932 y al general Sanjurjo. Finalmente, resaltó su defensa de la unidad de España y aseguró que «se dará el placer de ver fracasar el estatuto catalán». ${ }^{107}$ Estaba convencido que serían los propios catalanes quienes pedirían al gobierno central la supresión de la autonomía, ya que no serían capaces de administrarla, pero «es menester que pidan ellos que les quitemos el Estatuto y iya lo pedirán!». ${ }^{108}$ Se equivocaba. No recordaba lo que escribió Costa en el libro que le prologó en 1900 sobre la autonomía de las Antillas.

Macià murió durante la navidad de 1933. El presidente de la Generalitat y antiguo oficial del ejército español era católico - su hermana era monja-, creencias que compartía el primer presidente de la II República, Niceto Alcalá Zamora que acudió a su sepelio. Cuando Royo supo que el presidente de la República había rezado ante el cadáver de Macià reaccionó muy airadamente y protagonizó el escándalo más grande que «se haya producido en palacio» presidencial, ya que perdió completamente la razón y increpó a Alcalá Zamora «en términos de inconcebible violencia», con unos gritos que «oyó todo el mundo y que no pudo contener su aterrado jefe Martínez de Velasco». ${ }^{109}$

En enero de 1934, los agraristas constituyeron el Partido Agrario Español (PAE) liderado por Martínez de Velasco, y con Royo como vicepresidente. A mediados de septiembre, en el contexto de rechazo de los propietarios agrícolas catalanes hacia la ley de contratos de cultivos de la Generalitat, y ante el temor de que la Lliga acaparara el respaldo de dichos terratenientes, los líderes agraristas querían organizar una sección del PAE en Cataluña. ${ }^{110}$ Sin embargo, su constitución se vio postergada por los sucesos de octubre. Finalmente, el grupo que constituyó la sección catalana del PAE declaró que la autonomía y el unitarismo eran compati-

107 M.T. Gutiérrez Rodríguez, «Perfil y trayectoria...», op. cit., p. 606.

108 Antonio Royo Villanova, Diario de Sesiones del Congreso, 27/6/1934, pp. 41224123.

109 Niceto Alcalá Zamora, Memorias, Planeta, Barcelona, 1977, p. 265.

110 Sobre el agrarismo en Cataluña véase Isidre Molas (ed.), Diccionari dels partits polítics de Catalunya. Segle XX, Enciclopèdia Catalana, Barcelona, 2000, p. 185 y en el resto de España Luis Teófilo Gil Cuadrado, «Antonio Royo-Villanova...», op. cit., p. 400 y El Partido Agrario...op. cit., pp. 287-307. 
bles, si la primera se limitaba a una descentralización administrativa, en la línea defendida por Royo. ${ }^{111}$

En relación con la ley de contratos de cultivos, Royo aseguraba que el Parlamento catalán «invadió las facultades soberanas de las Cortes españolas» vulnerando tanto la Constitución como el Estatuto, y ante la sentencia del Tribunal de Garantías Constitucionales que declaraba la nulidad de la ley catalana, «todos los organismos de la Generalidad se declararon en franca rebeldía». ${ }^{112}$ Companys, el 6 de octubre, cuando proclamó el Estado Catalán dentro de la federación española, se habría mostrado, según Royo, como un digno sucesor de Macià. ${ }^{113}$

Durante la insurrección de octubre de 1934, los diputados agrarios mostraron su total apoyo al Gobierno radical-cedista, porque tal como aseveró el propio Royo, el 9 de octubre en el Congreso, en su opinión «lo primero es la Patria, lo segundo la libertad y lo tercero la República». ${ }^{114}$ En la madrugada del 6 de octubre de 1934, le despertó una llamada telefónica del general Sanjurjo desde su exilio en Portugal. Éste le habría dicho que quería ofrecerse al Gobierno para reprimir la sublevación catalana, ya que los hechos del 6 de octubre demostrarían que su insurrección del 10 de agosto de 1932 estaría plenamente justificada. Royo le aseguró que le comunicaría a Lerroux lo que le había dicho. Lo hizo y el líder radical le pidió que no informara a nadie de lo que le había comunicado Sanjurjo. ${ }^{115}$

Al suspenderse temporalmente la autonomía catalana, Royo aseguraba que los catalanistas habían mostrado su incapacidad para autogobernarse, y que los agrarios «hemos acertado en los peligros que señalamos; cojamos ahora el Estatuto, no para destruirlo, sino sólo para revisarlo serena, consciente y reflexivamente». ${ }^{16}$ Nuevamente defendía la descentralización administrativa, pero no la política. ${ }^{117}$

111 Luis Teófilo Gil Cuadrado, «Antonio Royo-Villanova...», op. cit., p. 396 y El Partido Agrario..., op. cit., p. 442.

112 Antonio Royo Villanova, Treinta años de política..., op. cit., p. 191.

113 Ibídem, p. 192.

114 Antonio Royo Villanova DSC, 9/10/1934, p. 4493, citado en Luis Teófilo Gil Cuadrado, El Partido Agrario..., op. cit., p. 328.

115 Antonio Royo Villanova, Treinta años de política..., op cit., p. 193. Otra versión de los mismos hechos en S. A., «Anecdotario de...», op. cit., p. 65.

116 Antonio Royo Villanova, Treinta años de política..., op. cit., p. 205. Véase también Luis Teófilo Gil Cuadrado, «Antonio Royo-Villanova...», op. cit., pp. 401-402.

117 Antonio Royo Villanova, DSC, 7/12/1934, p. 5339. 
El 17 de febrero de 1935, finalmente, los líderes del PAE visitaron a sus correligionarios en Cataluña. Éstos les organizaron un banquete político, en el que Royo volvió a dar rienda suelta a su anticatalanismo, al afirmar que los defensores del Estatuto catalán eran los peores enemigos de España. También se opuso a la existencia de una Universidad autónoma catalana, a la que calificó de Universidad catalanista. Desde su perspectiva la Universidad Autónoma de Barcelona tendría que «regirse como la de Valladolid y las restantes de España. Si algunos catalanes quieren una Universidad distinta, que la construyan y la costeen». Irónicamente, afirmó que su objetivo era jubilarse como catedrático en la Universidad de Barcelona y sentenciaba que «Cataluña no puede separarse de España, y el día que se separe, se suicidará». ${ }^{118}$

La implantación de los agraristas en Cataluña era mínima, porque su espacio político lo ocupaban Acción Popular Catalana, la sección catalana de la CEDA, o la misma Lliga. Además, el anticatalanismo que impulsó la popularidad de Royo en gran parte de España, generó un rechazo generalizado entre la mayoría de catalanes. En este período, Royo diferenciaba a los agraristas del resto de opciones conservadoras, ya que los radicales, encabezados por Lerroux, estuvieron a favor del Estatuto de autonomía catalán y del artículo 26 de la Constitución de 1931, que suprimía todo apoyo económico estatal a la Iglesia Católica y a las órdenes religiosas. Además, éstas pasaban a tener la condición de asociaciones y no podían dedicarse al ejercicio de la enseñanza. También marcaba diferencias con «nuestros amigos de la CEDA», porque se declaraban regionalistas y no «tienen la fe que nosotros en la libertad, en la democracia y en el Parlamento». Reconocía que tenían en común con «todas las derechas la defensa de la Patria» y la voluntad de revisar la Constitución. También compartían con los radicales y los republicanos liderados por Melquíades Álvarez la «defensa de la libertad». En cambio, no tenían nada en común con los «nacionalistas catalanes, vascos o gallegos, que niegan a la Patria, ni con los socialistas, que niegan a la libertad». ${ }^{119}$

Lerroux negoció con Martínez de Velasco para que los agraristas se integrasen en el Gobierno. El líder del PAE aceptó la propuesta, pero impuso que uno de los nuevos ministros fuese Royo, aunque éste no era del agrado ni del presidente de la República, Alcalá Zamora, ni del jefe del

118 Citado en Luis Teófilo Gil Cuadrado, El Partido Agrario..., op. cit., p. 452.

119 Antonio Royo Villanova, «El Partido Agrario», Horizontes, n. ${ }^{\circ} 3,21 / 1 / 1935$, cit. en Luis Teófilo Gil Cuadrado, El Partido Agrario..., op. cit., p. 596. 
Gobierno, Lerroux. Le otorgaron la cartera de Marina, ya que era considerada como el ministerio más inocuo. Los adversarios de Royo «hicieron chacota a costa del navegante del Pisuerga y del almirante del Ebro». ${ }^{120} \mathrm{El}$ mismo Royo reconocía que le habían propuesto que formase parte del Gobierno, en un ministerio poco relevante, para mitigar el antiautonomismo de los aragoneses, ${ }^{121}$ entre los que Royo contaba con un gran apoyo popular.

En septiembre de 1935, el ministro de Estado le pidió que representase al Gobierno en unos funerales en Bélgica, ya que "“usted es el ministro más desocupado". Se convenció». Al regresar leyó en la Gaceta el decreto traspasando el servicio de Carreteras a la Generalitat, con lo que se ponía de manifiesto que el Gobierno no modificaría substancialmente el Estatuto de Autonomía catalán. Royo dimitió inmediatamente ${ }^{122}$ y, a mediados de diciembre de 1935, abandonó la minoría agraria, tras la entrada de Martínez de Velasco en el nuevo Gobierno de Manuel Portela Valladares (1867-1952), porque éste también estaba integrado por miembros de la Lliga, ${ }^{123}$ con lo que volvía a mostrar su furibundo anticatalanismo.

Una vez disueltas las Cortes, Royo solicitó recuperar su cátedra, petición que le fue concedida el 20 de enero de 1936. Cuando, finalmente, se volvieron a convocar elecciones generales, el 16 de febrero, afirmó que el «Frente Popular era una idea rusa». También aseguraba que los parlamentarios catalanistas mediatizaban la política española al decidir con «sus votos las crisis ministeriales y entrometiéndose en los problemas de más enjundia y más alejados de los intereses regionales. Como a una colonia tratan a España los catalanistas». ${ }^{124}$ El paladín del centralismo político acusaba a los nacionalistas subestatales de colonizadores.

Por iniciativa del líder de la CEDA pasó a formar parte de la lista electoral de las derechas en la circunscripción de Madrid, ya que Gil-

120 S. A., «Anecdotario de...», op. cit., p. 65.

121 Antonio Royo Villanova, Treinta años de política..., op. cit., p. 218. Véase también Luis Teófilo Gil Cuadrado, «Antonio Royo-Villanova...», op. cit., p. 402.

122 Antonio Royo Villanova, Treinta años de política..., op. cit., p. 220. S. A., «Anecdotario de...», op. cit., p. 65. Véase también Luis Teófilo Gil Cuadrado, «Antonio RoyoVillanova...», op. cit., pp. 402-403 y El Partido Agrario..., op. cit., p. 369.

123 Antonio Royo Villanova, Treinta años de política..., op. cit., p. 220. véase también Luis Teófilo Gil Cuadrado, «Antonio Royo-Villanova...», op. cit., p. 404 y El Partido Agrario..., op. cit., p. 369.

${ }^{124}$ S.A., ABC, 7/1/1936, p. 4. También Antonio Royo Villanova, Treinta años de política..., op. cit., p. 308. 
Robles pensaba que Royo era «un gran candidato por sus campañas españolistas», ${ }^{125}$ y le convenció para que no se presentase en Valladolid, que era su auténtico feudo. ${ }^{126}$

En las elecciones generales, el Frente Popular se impuso al Frente Nacional, y la ley electoral del período les premió con una amplia mayoría parlamentaria, pero habían ganado las elecciones por un margen de votos no demasiado amplio. ${ }^{127}$ Royo no revalidó su escaño y en una carta a uno de sus hermanos aseguraba que si «Dios ha permitido mi derrota, será que así me conviene». Le pidió que pusiese una «vela a la Virgen del Pilar en acción de gracias» por su derrota electoral. Sus admiradores afirmaban que el «no haber sido diputado le salvó la vida», ya que al iniciarse la Guerra Civil no se encontraba en la capital española. ${ }^{128}$ En este período, Royo defendía un discurso «hipernacionalista», en el que «Castilla funciona como el prototipo de la España contrarrevolucionaria», y no dudaba en afirmar que los castellanos eran un pueblo «asimilista, imperialista, unitario y uniformizador». ${ }^{129}$

Con la victoria del Frente Popular Companys recuperó la presidencia de la Generalitat, ${ }^{130}$ y Royo, en una carta publicada en el $A B C$, anunció que se retiraba de la vida política. También expresó su descontento con los diputados de la derecha que habían apoyado la reinstauración de la autonomía catalana, y anunció que se dedicaría a los «grandes ideales de toda mi vida: la Patria y la libertad». ${ }^{131}$

Royo pensaba que las Cortes surgidas de las elecciones de febrero de 1936 no eran comparables con sus predecesoras, porque estaban integra-

125 José María Gil Robles, No fue posible la paz, Barcelona, Ariel, Barcelona, 1968, pp. 418-419. Véase también Luis Teófilo Gil Cuadrado, «Antonio Royo-Villanova...», op. cit., p. 404.

126 S. A., «Anecdotario de...», op. cit., p. 65 y Luis Teófilo Gil Cuadrado, «Antonio Royo-Villanova...», op. cit., p. 404.

127 Gabriele Ranzato, El eclipse de la democracia. La guerra civil y sus orígenes (1931-1939), Siglo XXI Editores, Madrid, 2006, p. 240.

128 S. A., «Anecdotario de...», op. cit., p. 65.

129 José Miguel Sánchez Estévez, «Castilla y León en la época contemporánea. Periferización económica: Contrarrevolución. Transición política», Aula: Revista de Pedagogía de la Universidad de Salamanca, n. ${ }^{\circ}$ 5, 1993, pp. 83-84 y 97.

130 José María Gil Robles, No fue posible..., op . cit., p. 533. Véase también, Hilari Raguer, «De revolucionari a home de Govern», Josep María Solé i Sabaté (dir.), Lluís Companys. President de Catalunya. Biografia humana i política, vol. I, Generalitat de Catalunya, Enciclopèdia Catalana Barcelona, 2006, p. 86.

${ }^{131}$ Antonio Royo Villanova, $A B C, 28 / 2 / 1936$, p. 52. 
das básicamente por «socialistas, separatistas y ateneístas, cuyo verdadero aglutinante era la negación de la Patria española». Explicaba que los primeros consideraban la patria como un «prejuicio burgués» y los acusaba de disolverla «anegándola en el cosmopolitismo utópico de la Internacional». Los nacionalistas subestatales, tanto de derechas como de izquierdas, eran para Royo separatistas que «partían, despedazaban, pulverizaban la Patria con esa monserga de las nacionalidades ibéricas y con el ridículo invento de los Estatutos». Finalmente, los ateneístas, en referencia al grupo liderado por Azaña, eran descritos como «espíritus fuertes educados en el escepticismo pedante de la llamada generación del 98, habían declarado reiteradamente que el ser patriota era una cursilería». ${ }^{132}$

Después del inicio de la guerra civil, apoyó a los insurrectos que se autodenominaban nacionales. El 4 de agosto de 1936, por orden del ministro de Instrucción pública del gobierno de la República era desposeído de su cátedra por «desafecto al régimen». Royo replicó con un telegrama al presidente de la Junta de Defensa de Burgos en el que le comunicaba: «Declarado cesante por el Gobierno ruso, reitero mi adhesión al Gobierno de España». ${ }^{133}$ Tenía estrechos vínculos con el general Sanjurjo, el militar designado para encabezar la rebelión, hasta que, el 20 de julio, un accidente, en la avioneta que le llevaba de regreso a España, acabó con su vida.

Royo reconocía que nunca había sido fascista. No obstante, pensaba que el objetivo de la guerra iniciada en el verano de 1936 era «salvar a España y la Patria está por encima de todas las ideas y por encima de todos los partidos». Reiteraba que con los que no compartía nada era «con los separatistas, que son enemigos de mi Patria, ni con los comunistas, que son enemigos de la libertad». 134

No tuvo reparos en asegurar que el general Franco tenía que superar obstáculos que «ni Hitler ni Mussolini encontraron en su camino», porque no había separatistas ni en Alemania, ni en Italia, mientras que en España, «no sólo existían, sino que llevaban más de treinta años mediatizando a los Gobiernos de Madrid, que daban una sensación de atolondramiento y de pánico» en cuanto había agitación o «cuatro gritos» en Barcelona. Pensaba que sin el «separatismo, esta guerra hubiera durado bien poco. Sin

\footnotetext{
132 Antonio Royo Villanova, Treinta años de política..., op. cit., p. 309.

${ }^{133}$ S. A., «Anecdotario de...», op. cit., p. 65.

134 Antonio Royo Villanova, Treinta años de política..., op. cit., pp. 281-282.
} 
el Estatuto de Cataluña, la Guardia Civil de Barcelona, en vez de ponerse enfrente del Ejército, se hubiera unido a él como el 6 de Octubre»..$^{135}$

En agosto de 1936, Alejandro Royo-Villanova Fernández-Cavada, uno de sus hijos, que era juez de instrucción de Colmenar Viejo, fue asesinado. Le dedicó su último libro y en la dedicatoria afirmaba que «en un día de silencioso sacrificio hiciste más, mucho más por España que tu padre en medio siglo de hablar y de escribir». ${ }^{136}$

No tuvo problemas con el régimen franquista. Mantuvo su cátedra hasta que se retiró, y potenció la carrera académica del hijo que sobrevivió a la guerra civil. ${ }^{137}$ Murió en Madrid, el 7 de noviembre de 1958, a la avanzada edad de 89 años. El obituario que le dedicó $A B C$ lo definía como un «patriota ejemplar», un «orador elocuente», especialmente en sus discursos «en contra de las conjuras separatistas». ${ }^{138}$

\section{A modo de conclusiones}

Antonio Royo Villanova llegó a ser muy popular, hasta el punto que sus descendientes, tanto hijos como sobrinos, decidieron conservar sus dos apellidos. Nunca renunció a sus orígenes aragoneses y a su vínculo con el regeneracionismo costista, pero decidió ser vallisoletano, ciudad en la que desarrolló casi toda su carrera académica, como uno de los principales referentes del Derecho Administrativo español.

En el ámbito político, su preocupación fundamental fue la organización territorial del Estado. A pesar de ser uno de los principales defensores de la descentralización administrativa, encabezó durante décadas un discurso vehementemente contrario a la descentralización política y cultural, aunque personalmente era políglota y conocía suficientemente bien la lengua catalana como para traducir la principal obra de Enric Prat de la Riba. Nunca aceptó que el Estado - España - fuese, tal como defendía Prat, una forma de organización política artificial, y la nación - catalana - un hecho natural.

135 Ibídem, p. 340.

136 S. A., «Anecdotario de...», op. cit., p. 65.

137 Antonio Royo Villanova y Segismundo Royo Villanova, Derecho administrativo del nuevo estado español. Apéndice a los elementos de derecho administrativo, Librería Santarén, Valladolid, 1939.

138 S. A., $A B C, 8 / 11 / 1958$, p. 49. 
Fue elegido como diputado de las Cortes Constituyentes de 1931 y reelegido en 1933, como dirigente del agrarismo español. Llegó a ser ministro, aunque en una cartera poco relevante. Era uno de los máximos defensores del unitarismo identificado con el lema: España una. El movimiento que se insurreccionó contra la legitimidad republicana en 1936 se autoidentificaba como los nacionales, y algunos periódicos afirmaban que eran el bando nacionalista, es decir, que uno de los principales elementos aglutinadores de los que posteriormente serán conocidos como franquistas era el nacionalismo español, con un discurso simple y excluyente que buscaba la destrucción de los que no compartían sus principios, especialmente los rojos y/o separatistas, aunque desde el franquismo se defendían diferentes maneras de entender la nación. De hecho, el nacionalismo español, del que Royo Villanova fue una figura relevante, puede ser visto como una manifestación del problema de la nacionalización española, entendiendo que la experiencia española es una de las más complejas de la Europa contemporánea.

Al margen de su trayectoria política, Royo fue un destacado periodista, con una vinculación muy larga y continuada por sus descendientes con el vallisoletano Norte de Castilla, el periódico más relevante de Castilla y León. También fue un maestro de administrativistas, ya que su concepción del derecho administrativo español fue posiblemente la predominante en la academia española, desde la publicación de su manual de derecho Administrativo, en 1900, hasta la muerte de su hijo, Segismundo. No hay ninguna biografía amplia sobre Antonio Royo Villanova, cuando tanto su pensamiento político, entre los defensores del unitarismo, como su legado periodístico y académico han sido muy amplios. Fue, en suma, un regeneracionista, un académico relevante defensor de la descentralización de la administración, siempre que no cuestionase la unidad española, un político que llegó a ministro y un maestro tanto de anticatalanistas, como de administrativistas. 